\title{
Restoration of Lung Pressure-Volume Characteristics with Surfactant: Comparison of Nebulization Versus Instillation and Natural Versus Synthetic Surfactant
}

\author{
MACHIKO IKEGAMI, TOM HESTERBERG, MASAHIKO NOZAKI, AND FORREST H. ADAMS ${ }^{(15)}$ \\ Division of Cardiology, Department of Pediatrics, University of California, Los Angeles, California, USA
}

\begin{abstract}
Summary
The pressure-volume (PV) characteristics of 21 adult rat lungs were examined before and after lung washing after which natural or synthetic (dipalmitoyl lecithin (DPL)) surfactant was administered by either an ultrasonic nebulizer or instilled directly into the trachea. Lungs receiving surfactant by nebulization were ventilated at a rate of $40 / \mathrm{min}$ at $20 \mathrm{~cm} \mathrm{H} \mathrm{H}_{2} \mathrm{O}$ peak inspiratory pressure and with $7 \mathrm{~cm} \mathrm{H}_{2} \mathrm{O}$ positive end expiratory pressure (PEEP) for $2 \mathrm{hr}$. Lungs receiving surfactant by instillation were ventilated for $5 \mathrm{~min}$ in a fashion similar to the nebulization study; then a final PV curve was obtained.

Results from the deflation limb of the PV curves at 5 and 10 $\mathrm{cm} \mathrm{H}_{2} \mathrm{O}$ were analyzed and expressed as a percentage of the original total lung capacity obtained at $30 \mathrm{~cm} \mathrm{H} \mathrm{H}_{2} \mathrm{O}$ (percentage of TLC). The control values of percentage of TLC were $52.8 \pm$ 6.4 at $5 \mathrm{~cm} \mathrm{H}_{2} \mathrm{O}$ and $73.9 \pm 3.9$ at $10 \mathrm{~cm} \mathrm{H}_{2} \mathrm{O}$. Neither nebulization nor instillation of DPL produced a significant increase in percentage of TLC. Nebulization of natural surfactant produced only a slight increase in percentage of TLC from $4.8 \pm$ 2.4 to $6.7 \pm 2.1$ (not significant) at $5 \mathrm{~cm} \mathrm{H}_{2} \mathrm{O}$ and from $21.1 \pm$ 6.1 to $27.8 \pm 5.4(P<0.05)$ at $10 \mathrm{~cm} \mathrm{H}_{2} \mathrm{O}$. Instillation of natural surfactant produced a very striking increase of percentage of TLC from 13.2 \pm 8.0 to $55.6 \pm 4.3(P<0.01)$ at $5 \mathrm{~cm}$ $\mathrm{H}_{2} \mathrm{O}$ and from $47.9 \pm 6.1$ to $78.6 \pm 4.2(P<0.01)$ at $10 \mathrm{~cm}$ $\mathrm{H}_{2} \mathrm{O}$.
\end{abstract}

\section{Speculation}

From these studies, it appears that nebulization is not an effective method for depositing surfactant into the alveoli. On the other hand, direct instillation of the material into the tracheal bronchial tree seems to be a promising method worthy of further study as a method for treatment of the respiratory distress syndrome.

As the development of respiratory distress syndrome (RDS) is probably due to a prenatal deficiency of surfactant, one form of treatment might be the administration of surfactant through the airways. Several such attempts have been made experimentally and clinically. It has been shown that deposition of natural surfactant into the trachea of prematurely born rabbits before the first breath enhances the air expansion of their lungs (2). A favorable effect of nebulization of DPL was also demonstrated using excised dog lung (12), whereas clinical effects on infants with RDS by using an aerosol of DPL in Freon were inconsistent (1). This study was designed to determine whether the nebulization or instillation of surfactant (natural surfactant or DPL) may restore the PV characteristics of adult rat lungs in which surfactant was removed by saline washings.

\section{MATERIALS AND METHODS}

Adult male rats weighing $350-500 \mathrm{~g}$ were used in this study. Seven were used for pilot studies, 11 for the nebulization studies, and 10 for the instillation studies. After injecting $60 \mathrm{mg}$ sodium barbital into the peritoneal cavity, each rat was killed by transecting the abdominal aorta and allowing exsanguination to occur. The heart and lungs were removed carefully en bloc.

\section{PRESSURE-VOLUME MEASUREMENTS}

The trachea was cannulated with polyethylene tubing and the lungs were degassed in a vacuum jar and placed in a saline water bath at $21^{\circ}$. The tracheal cannula was connected to a constant infusion syringe of $50 \mathrm{ml}$ and to a water manometer by a $\mathrm{T}$ tube. The lungs were inflated with air gradually over $16-23$ min to 30 $\mathrm{cm} \mathrm{H}_{2} \mathrm{O}$ in increments of $0.9 \mathrm{ml}$ and then deflated in a similar fashion. The volume reached at $30 \mathrm{~cm} \mathrm{H}_{2} \mathrm{O}$ pressure was assumed as the total lung capacity. Pressure readings were made every minute to determine the volume on both inflation and deflation. Lungs that leaked were excluded.

A pressure-volume curve was derived from the pressure and volume measurements using a computer plotter Wang model 600 . On the deflation limb of the pressure-volume curve, the volume at a pressure of $5 \mathrm{~cm} \mathrm{H}_{2} \mathrm{O}$ and $10 \mathrm{~cm} \mathrm{H}_{2} \mathrm{O}$ was expressed as a percentage of total lung capacity. The values of the volume were corrected by subtracting the volume displacement of the water manometer. Pressure-volume measurements were made three times on each lung: initially; after lung washing (removal of surfactant); and after treatment with surfactant.

\section{REMOVAL OF SURFACTANT}

After an initial pressure-volume curve recording, $10 \mathrm{ml}$ of saline was infused into the lung and withdrawn gently several times through a cannula by hand. Fujiwara et al. (3) found that repeating this procedure 10 times produced a lung wash that was relatively free of surfactant on the 10 th washing. Thus, to insure maximum removal of surfactant in our study, the procedure was repeated 20 times giving a total wash volume of $200 \mathrm{ml}$ saline. At the end of the washings the effluent was clear and the pressure-volume curve showed poor stability. It was decided that lungs with volumes at $5 \mathrm{~cm} \mathrm{H} \mathrm{H}_{2} \mathrm{O}$ over $25 \%$ of total lung capacity after washings would be excluded from this study.

\section{PREPARATION OF NATURAL SURFACTANT}

The excised lungs of a calf 2 days old were washed with saline after exsanguination. Since the lung wash had a very large volume $(2,500 \mathrm{ml})$, it was first centrifuged at $2^{\circ}$ for $60 \mathrm{~min}$ at $11,000 \mathrm{rpm}$ by using a Sorvall GSA rotor. The pellet was resuspended in cold saline, layered over $0.75 \mathrm{M}$ sucrose $(20 \mathrm{ml})$, 
and then centrifuged at 20.000 rpm by using a Spinco SWV $25-1$ roter at $2^{\circ}$ for 60 min. The material concentrating at the interface between saline and $0.75 \mathrm{M}$ sucrose was aspirated by a disposable pipelte and resuspended with saline in a volumetric flask. The total amount of phospholipid present was 596 mg. The phospholipid concentration of this solution wats $2 \mathrm{mg} / \mathrm{ml}$. and the minimal surface tension was 0 dyens/cm on a modified Wilhelmy balance.

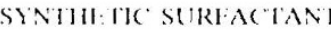

Synthetic surfactant, supplice by Armour Pharmatceutical Company (Kankakee. Ill.), Wals diluted so that each ml contained $5 \mathrm{mg}$ dipalmitoyl-dl-3-lecithin in buffered saline. Taken directly from the bottle. this suspension exhibited peor surface activity (i.t'., the minimal surface tension was 1.3 dynes/cm): however, when the suspension was extracted with chloroform and spread on the surface of saline, it showed high surface activity (i.e., the minimal surface tension 1 as $1 \mathrm{dyne} / \mathrm{cm}$ ).

\section{IRI:ATMINTOE IUNG}

Four groups of animals were studied: mebulization with natural surfactant (five rats), nebulization with ssmbetic surfactant (six rats). instillation with natural surfactant (fice rats), and instillation with synthetic surfactant (five rats).

In the nchulization groups. $f(1 \mathrm{ml}$ surfactant suspension were used for each rat. For those receiving natural surfactant. the fo ml contaned so me phospholipid and for those receiving synthetic surfactant. the $40 \mathrm{ml}$ containcel $200 \mathrm{mg}$ DPI. In each experiment, the suspension was initially sonified by a Heat Sy'stem Sonifier (model W-1S5t). The suspension was then placed into a $3 \mathrm{Mll}$. I.KB Medical Ularasonic Nebulizer (model NB108) and it was continuously nebulized into the lungs wheh were ventilated for 2 hr on a llarvard small animal respirater. Tho
Table 1. Total lang capacity before and after lung wash and trientme'tht

\begin{tabular}{|c|c|c|c|c|c|}
\hline $\begin{array}{l}\text { Exp. } \\
\text { no. }\end{array}$ & $\begin{array}{c}\text { Initial. } \\
\mathrm{ml}\end{array}$ & $\begin{array}{c}\text { After } \\
\text { lung } \\
\text { Wash, ml }\end{array}$ & $\begin{array}{l}\text { After } \\
\text { treat- } \\
\text { ment. } m l\end{array}$ & Trcatment & Surfactant' \\
\hline 1 & $16 . .5$ & 16.9 & 17.2 & Instillation & Nattural \\
\hline 3 & 14.0 & 13.0 & 8.5 & Nchulization & Natural \\
\hline 5 & 8.5 & 6.7 & 5.1 & Ncbulization & Naturat \\
\hline 6 & 17.5 & 16.1 & 12.8 & Nebulization & Natural \\
\hline 7 & 15.7 & 1.3 .3 & 10.8 & Nicbulization & Nattural \\
\hline s' & 19.0 & 16.4 & 15.7 & Nebulization & I)PL \\
\hline c) & 15.4 & 10.0 & 7.0 & Nohulization & Natural \\
\hline 10 & 17.1 & 12.4 & 10.0 & Ncbulization & DPL. \\
\hline 11 & 15.2 & 11.6 & 8.5 & Nebulization & DPI. \\
\hline 1.2 & 19.6 & 1.3 .7 & $+.66^{2}$ & Ncbulization & I)PL \\
\hline 1.3 & 14.4 & 11.6 & $5.7^{3}$ & Nebulization & D)PI. \\
\hline 14 & $5.4=$ & $4.5^{2}$ & $+.2=$ & Nchulization & DPL \\
\hline 22 & 13.8 & 14.3 & 12.1 & Instillation & Natural \\
\hline 2.3 & 15.6 & 11.9 & 15.6 & Instillation & Natural \\
\hline 26 & 17.2 & 13.9 & 13.0 & Instillation & Nattural \\
\hline 27 & 14.6 & 12.3 & 10.9 & Instillation & DPL \\
\hline 32 & 17.3 & 1.3 .6 & 16.4 & Instillation & Natural \\
\hline 3.3 & 17.8 & 15.9 & 18.3 & Instillation & Natural \\
\hline 34 & 17.4 & 14.6 & 1.3 .6 & Instillation & I)PI. \\
\hline 35 & 15.5 & 1.3 .7 & 1.3 .3 & Instillation & DPL. \\
\hline 36 & 17.8 & 1.3 .7 & 12.7 & Instillation & 1)PL \\
\hline Mcian & 16.0 & 1.3 .3 & 12.3 & & \\
\hline SI) & \pm 2.4 & \pm 2.3 & \pm 3.6 & & \\
\hline
\end{tabular}

1 Natural: natural surfactant: I)Pl.: dipalmitonl lecithin.

"Values are for keft lung (m)ly; not used in calculation of me:an $\pm \mathrm{S1}$ ).

"Values are for left lower lobe only; not used in calculation of mean \pm Si).

Table 2. Percentage of total lung capacity (TLC) of excised rat lungs at 5 and $10 \mathrm{~cm}$ H.O before and after nethulization of natural

\begin{tabular}{|c|c|c|c|c|c|c|c|c|}
\hline \multirow[b]{2}{*}{ Exp. no. } & \multicolumn{4}{|c|}{ " TLC at $5 \mathrm{~cm} \mathrm{HI}()$} & \multicolumn{4}{|c|}{$\because$ TLC at $10 \mathrm{~cm} \mathrm{H.O}$} \\
\hline & Initial & $\begin{array}{l}\text { After } \\
\text { Wath }\end{array}$ & $\begin{array}{l}\text { After } \\
\text { treatment }\end{array}$ & Change & Initial & $\begin{array}{l}\text { Alter } \\
\text { wash }\end{array}$ & $\begin{array}{c}\text { After } \\
\text { treatment }\end{array}$ & (hange \\
\hline 3 & 62.5 & 6.3 & 10.0 & +3.7 & 80.9 & 23.1 & 33.1 & +10.0 \\
\hline 5 & 48.1 & 5.6 & 7.5 & +1.9 & 70.6 & 18.1 & 20.6 & +2.5 \\
\hline 6 & 55.6 & 2.8 & 6.2 & +3.4 & 75.0 & 23.1 & 29.4 & +6.3 \\
\hline 7 & 52.5 & 7.5 & 4.4 & -3.1 & 71.0 & 28.8 & 32.2 & +3.4 \\
\hline 9) & 47.5 & 1.9 & 5.6 & +3.7 & 71.6 & 12.5 & 2.3 .8 & +11.3 \\
\hline Méan & 52.2 & 4.8 & 6.7 & +1.9 & 73.9 & 21.1 & 27.8 & $+6.7^{1}$ \\
\hline SI) & \pm 0.1 & \pm 2.4 & \pm 2.1 & \pm 2.9 & \pm 4.2 & \pm 0.1 & \pm 5.4 & \pm 3.9 \\
\hline
\end{tabular}

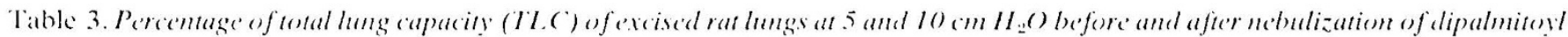
lecithin

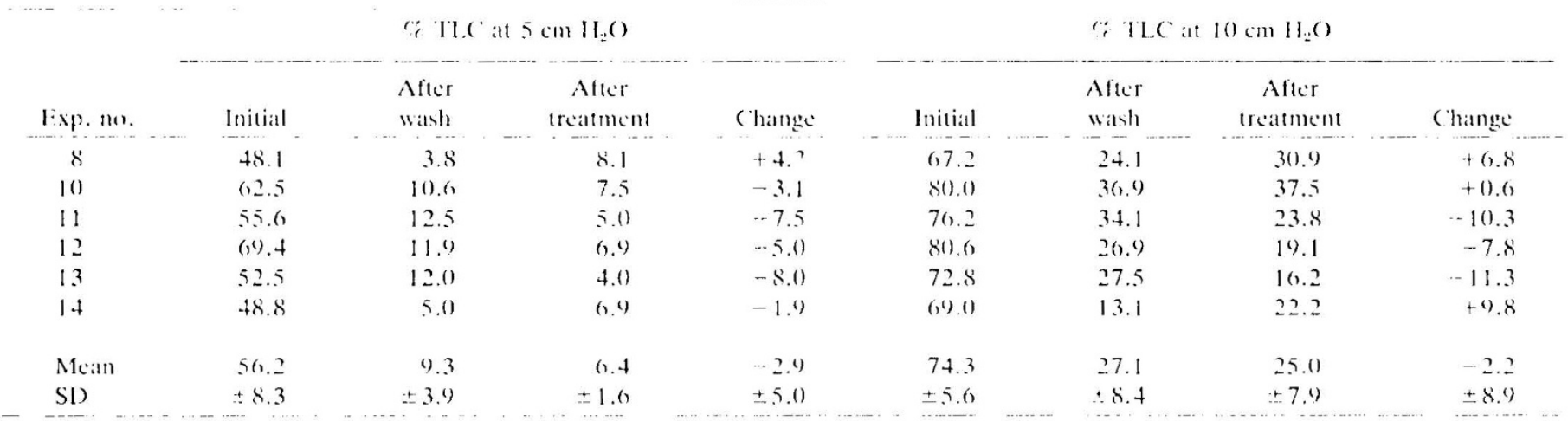


Table 4. Percentage of total lung capacity (TLC) of excised rat lungs at 5 and $10 \mathrm{~cm} \mathrm{H}_{2} \mathrm{O}$ be fore and after instillation of natural surfactant

\begin{tabular}{|c|c|c|c|c|c|c|c|c|}
\hline \multirow[b]{2}{*}{ Exp. no. } & \multicolumn{4}{|c|}{ (6) MIC at $5 \mathrm{~cm} \mathrm{H} \mathrm{H}_{2} \mathrm{O}$} & \multicolumn{4}{|c|}{$\because$ HLC at $10 \mathrm{~cm} \mathrm{H} \mathrm{H}_{2} \mathrm{O}$} \\
\hline & Initial & $\begin{array}{l}\text { Aficr } \\
\text { Wash }\end{array}$ & $\begin{array}{l}\text { After } \\
\text { treatment }\end{array}$ & Change & Initial & $\begin{array}{l}\text { After } \\
\text { wash }\end{array}$ & $\begin{array}{c}\text { After } \\
\text { treatment }\end{array}$ & Change \\
\hline 1 & 60.4 & 5.4 & 53.9 & +48.5 & 75.0 & 50.0 & 71.9 & +21.9 \\
\hline 22 & 43.1 & 18.8 & 59.4 & +40.6 & 68.8 & 51.3 & 81.9 & +30.6 \\
\hline 23 & 50.0 & $2+4$ & 56.9 & +32.5 & 75.0 & 46.3 & 80.0 & +33.7 \\
\hline 32 & 51.3 & 8.1 & 48.8 & +40.7 & 78.1 & 38.1 & 77.5 & +39.4 \\
\hline 3.3 & 55.6 & 9.4 & 58.8 & +49.4 & 77.5 & 5.3 .8 & 81.9 & +28.1 \\
\hline Mcan & 52.1 & 13.2 & 55.6 & $+42.3^{1}$ & 74.9 & 47.9 & 78.6 & +30.7 \\
\hline SI) & \pm 6.5 & $\pm 8.1)$ & \pm 4.3 & \pm 0.9 & \pm 3.7 & \pm 6.1 & \pm 4.2 & \pm 6.5 \\
\hline
\end{tabular}

$1 P<0.01$.

Table 5. Percentage of toral lung capacity (TLC) of excised rat lungs at 5 and 10 (cm $H_{2} O$ before and after instillation of dipalmitoyl lecithin

\begin{tabular}{|c|c|c|c|c|c|c|c|c|}
\hline \multirow[b]{2}{*}{ I:xp. no } & \multicolumn{4}{|c|}{$\because$ TLC at $5 \mathrm{~cm} \mathrm{H}_{2} \mathrm{O}$} & \multicolumn{4}{|c|}{$\because$ TLC at $10 \mathrm{~cm} 11_{2} \mathrm{O}$} \\
\hline & Initial & $\begin{array}{l}\text { After } \\
\text { Wash }\end{array}$ & $\begin{array}{l}\text { After } \\
\text { treatment }\end{array}$ & Change & Initial & $\begin{array}{l}\text { After } \\
\text { wash }\end{array}$ & $\begin{array}{l}\text { After } \\
\text { treatment }\end{array}$ & Change \\
\hline 26 & 45.6 & 18.8 & 18.8 & 0 & 71.3 & 50.0 & 50.0 & 0 \\
\hline 27 & 49.4 & 13.4 & 15.0 & +1.6 & 75.13 & 44.5 & 45.9 & +1.4 \\
\hline 34 & 48.8 & 14.1 & 16.9 & +2.8 & 70.6 & 51.9 & 53.8 & +1.9 \\
\hline 35 & 49.4 & 21.3 & 21.3 & () & 71.9 & 53.8 & 53.8 & 0 \\
\hline 36 & 51.3 & 13.4 & 11.9 & -1.5 & 74.4 & 50.0 & 49.4 & -0.6 \\
\hline Mean & 48.9 & 16.2 & 16.8 & +0.7 & 72.6 & 50.0 & 50.6 & +0.8 \\
\hline SI) & \pm 2.1 & \pm 3.6 & \pm 3.6 & \pm 1.9 & \pm 1.9 & \pm 3.5 & \pm 3.3 & \pm 1.0 \\
\hline
\end{tabular}

ventilation rate was $4(0 /$ min, the maximum inspiratory pressure was $20 \mathrm{~cm} \mathrm{H}_{2} \mathrm{O}$, and the PEYP was $7 \mathrm{~cm} \mathrm{H} \mathrm{H}_{2} \mathrm{O}$. The nebulized fog produced with both DPI, and natural surfactant when spread on a saline-filled trough of a modified Wilhelmy balance gave minimum surface tension below 10 dynes/cm.

In the instillation groups, $2 \mathrm{ml}$ surfactant suspension were instilled into the tracheal of each rat after which the fungs were ventilated for $5 \mathrm{~min}$ on the respirator in a fashion similar to the nebulization studies. For those receiving natural surfactant, the amount instilled contained $+\mathrm{mg}$ phospholipid and for those receiving synthetic surfactant, the amount instilled contained 10 mg DPL.

\section{RESUITS}

The assumed TI.C's of adult rat lungs (the volume at a pressure of $30 \mathrm{~cm} \mathrm{H} \mathrm{H}_{2} \mathrm{O}$ ) are listed in Table 1 . The mean initial TLC was $16.0 \mathrm{ml}$ and after the lung washing, the TLC decreased to $13.2 \mathrm{ml}$. Eight of the lungs were weighed immediately after removal from the rat. The mean lung weight was $1.89 \pm 0.35 \mathrm{~g}$. When the initial total lung capacities (i.e', before washing or treatment) were expressed as TI.C/lung weight, a mean of $9.1 \pm$ $1.6 \mathrm{~m} / \mathrm{g}$ lung tissuc was obtained.

The results of the lung pressure-volume characteristics during defleation at $5 \mathrm{~cm} \mathrm{H}_{2} \mathrm{O}$ and $10 \mathrm{~cm} \mathrm{H}_{2} \mathrm{O}$ before and after the nebulization and instillation of surfactant are shown in Tables 24. As shown in Table 2, the mean pereentage of TLC before the nebulization of natural surfactant was $4.8 \pm 2.4$ at $5 \mathrm{~cm} \mathrm{H} \mathrm{H}_{2} \mathrm{O}$ and $21.1 \pm 6.1$ at $10 \mathrm{~cm} \mathrm{HoO}$. The mean pereentage of TLC after nebulization of natural surfactant was $6.7 \pm 2.1$ at $5 \mathrm{~cm} \mathrm{I} \mathrm{I}_{22} \mathrm{O}$ and

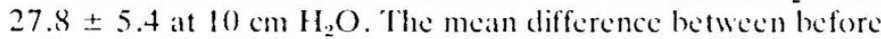
and after nebulization of natural surfactant wats $+1.9 \pm 2.9$ at 5

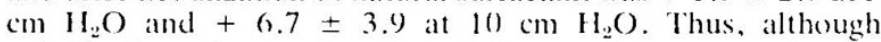
nebulization of natural surfactant increased the percentage of TLC at $5 \mathrm{~cm} \mathrm{H}_{2} \mathrm{O}$ and $10 \mathrm{~cm} \mathrm{H.O}(P<0.05)$, the increase was small.

As shown in Table 3, the mean pereentage of TLC before nebulization of $\mathrm{DPL}$ was $9.3 \pm 3.9$ at $5 \mathrm{~cm} \mathrm{H.}$ and $27.1 \pm 8.4$ at $10 \mathrm{~cm} \mathrm{H} H_{2} \mathrm{O}$. The mean pereentage of TLC after nebulizaton of DPl, was $6.4 \pm 1.6$ at $5 \mathrm{~cm} H_{2} \mathrm{O}$ and $25.0 \pm 7.9$ at $10 \mathrm{~cm} \mathrm{H}_{2} \mathrm{O}$. The mean difference between before and after nebulization of DPI, was $-2.9 \pm 5.0$ at $5 \mathrm{~cm} \mathrm{H} \mathrm{H}_{2} \mathrm{Oand}-2.2 \pm 8.9$ at $10 \mathrm{~cm} \mathrm{H} \mathrm{H}_{2} \mathrm{O}$, which was not significant.

As shown in Table t. the mean pereentage of TLC before instillation of natural surfactant wats $1.3 .2 \pm 8.0$ at $\left.5 \mathrm{~cm} \mathrm{I} \mathrm{I}_{2} \mathrm{O}\right)$ and $47.9 \pm 6.1$ at $10 \mathrm{~cm} \mathrm{H.O.} \mathrm{The} \mathrm{mean} \mathrm{pereentage} \mathrm{of} \mathrm{TLC} \mathrm{after}$ instillation of natural surfactant wass $5.5 .6 \pm 4.3$ at $5 \mathrm{~cm} \mathrm{H} \mathrm{H}_{2} \mathrm{O}$ and $78.6 \pm 4.2$ at $10 \mathrm{~cm} \mathrm{H}_{2} \mathrm{O}$. The mean difference between before and after instillation of natural surfactant was $42.3 \pm 6.9$ at $5 \mathrm{~cm}$ $\mathrm{H}_{2} \mathrm{O}(P<0.01)$ and $30.7 \pm 6.5$ at $10 \mathrm{~cm} \mathrm{H}_{2} \mathrm{O}(P<0.01)$. Instillation of natural surfactant produced a change in pereentage of TLC that was significantly greater than that produced by nebulization of natural surfactant at both 5 and $10 \mathrm{~cm} \mathrm{H.O}(\mathrm{P}<$ (0.01). Therefore, the instillation of natural surfactant significantly improved the pressure-volume characteristics of surfactant-depleted lung.

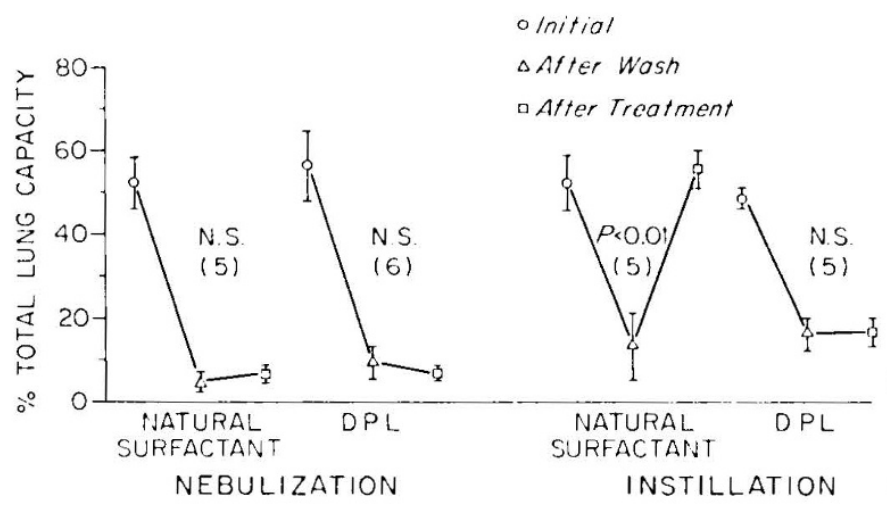

Fig. 1. A comparison of the pereentage of total lung capacity at $5 \mathrm{~cm}$ $\mathrm{H}_{2} \mathrm{O}$ for control lungs, lungs washed with $200 \mathrm{ml}$ saline, and washed lungs that were treated with natural surfactant and synthetic, dipalmitoyl lecithin $(D P L)$. 
As shown in Table 5 , the mean pereentage of Tl.C before instillation of DPL was $16.2 \pm 3.6$ at $5 \mathrm{~cm} \mathrm{H.} \mathrm{H}_{2} \mathrm{O}$ and $50.0 \pm 3.5$ at $10 \mathrm{~cm} \mathrm{H} \mathrm{H}_{2} \mathrm{O}$. The mean pereentage of TLC after instillation of DPL was $16.8 \pm 3.6$ at $5 \mathrm{~cm} \mathrm{H}_{2} \mathrm{O}$ and $50.6 \pm 3.3$ at $10 \mathrm{~cm} \mathrm{H}, \mathrm{O}$. The mean difference between before and after instillation of DPI, Was $0.7+1.9$ at $5 \mathrm{~cm} \mathrm{H.O}$ and $0.8 \pm 1.0$ at $10 \mathrm{~cm} \mathrm{H.O.}$. The pressure-volume characteristics did not change significantly after instillation of DPL.

A comparison of the results obtained in the four different treatment groups is shown in Figure 1. It indicates that the instillation of natural surfactant is the best way to restore the pressure-volume characteristics when compared with the other three methods.

\section{DISCUSSION}

This study has demonstrated that the instillation of natural surfactant into the lungs can restore the pressure-volume characteristics of adult rat lung previously depleted of surfactant by saline wash. Others have shown that saline lung lavage removes surfactant from the alveoli $(3,8)$. The PV characteristics of the surfactant-depleted rat lungs used in this study were similar to those in the lungs of infants dying of hyaline membrane discase (HMD) reported by Gribetz e't al. (7). They found that the volumes at $5 \mathrm{~cm} H_{2} \mathrm{O}$ and $10 \mathrm{~cm} \mathrm{H}_{2} \mathrm{O}$ on the deflation limb of the pressure-volume curve of HADD lungs were $0.4 \mathrm{ml} / \mathrm{g}$ and $0.5 \mathrm{ml} /$ g respectively, whereas the volumes of normal newborn were 1.9 $\mathrm{ml} / \mathrm{g}$ and $2.2 \mathrm{ml} / \mathrm{g}$. In rat 3.3 of our study (as shown in Figure 2). the volumes at $5 \mathrm{~cm} \mathrm{H}_{2} \mathrm{O}$ and $10 \mathrm{~cm} \mathrm{H}_{2} \mathrm{O}$ were $0.5 \mathrm{ml} / \mathrm{g}$ and 2.5 $\mathrm{ml} / \mathrm{g}$, respectively, after lung wash and $4.3 \mathrm{ml} / \mathrm{g}$ and $6.2 \mathrm{ml} / \mathrm{g}$ before wash when expressed in the same scale. It seems, therefore, that adult rat lungs depleted of natural surfactant by saline wash may be a good experimental model of the surfactantdeficient lungs of prematurely delivered infants.

Chu et al. (1) attempted to improve the ventilation of infants with RDS with an acrosol of DPL in Freon, but the results were inconsistent. Shannon et al. (12). however, reported that the lecithin fog gencrated by an ultrasonic nebulizer (frequency 3 $\mathrm{MHz}$ ) restored the pressure-volume characteristic of adult dog lung. For this reason, we used an LK13 high frequency 3-MH/2 ultrasonic nebulizer to acrosolize the surfactant suspension.

In the study of Shannon at al. (12), the excised dog lungs were ventilated for 3 hr to decrease lung surface activity. They expressed the change in volume over the fall in pressure from 8 to 3 $\mathrm{cm} \mathrm{H} \mathrm{H}_{2} \mathrm{O}$, and showed a $50 \%$ change in slope after ventilation with $\mathrm{O}_{22}$ and restoration of this slope after 90 min of ventilation with DPL fog. In contrast, our experiments did not show improvement of pressure-volume curves after ventilation with nebulized DPL. The discrepancy between our study and their study may be due to the difference in the technique of depletion of lung surfactant. If the depletion of surfactant was incomplete in Shamon's study, then the recovery of surface activity

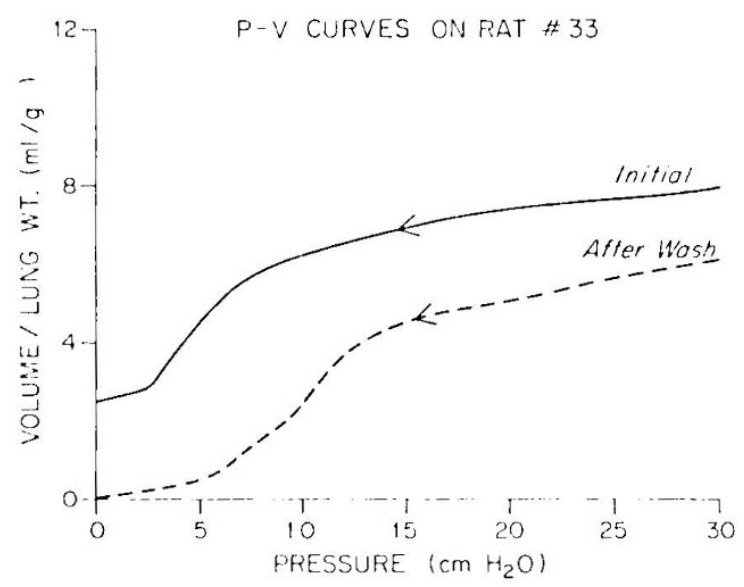

Fig. 2. Pressure-volumes $\left(P^{\prime}\right)$ curves on rat 33. might be easily accomplished by DPL nebulization. We believe our saline wash technique more effectively removed surfactant and thus produced less compliant lungs than did Shannon's technique. Thus, the greater instability of the washed lungs in our study may have prevented deposition of DPL by nebulization.

It has been suggested that the depletion of the lung surfaceactive lining layer is related to catabolism (5) or to disruption of the surface lining layer $(5,9)$. Repeated overinflation of excised lungs reduces compliance by an amount which is directly related to the tidal volume and to the duration and frequency of ventilation $(5,6,9)$. We therefore used a relatively low inflation pressure of $20 \mathrm{~cm} \mathrm{H}_{2} \mathrm{O}$ and an end expiratory pressure of $7 \mathrm{~cm}$ H.O to prevent the deterioration of the lining layer. We observed significant deterioration $(7 \%)$ of the deflation slope of the pressure-volume curve after 2 hr of ventilation with air, thus confirming the studies of Forest (6) and Pattle (10). The improvement of the pressure-volume characteristics of the lung by natural surfactant nebulization may therefore have been underestimated hecause of the deleterious effects of ventilation.

The favorable effects of tracheal instillation of natural surfactant were first reported by Enhörning ct al. (2). They found that the lung expansion of the premature rabbit fetus can be enhanced by tracheal deposition of homologous surfactant before the first breath. Premature fetuses given surfactant showed pressure-volume characteristics similar to those of full term fetuses. These studies have now been expanded to include various techniques for surfactant deposition in live born premature rabbits (11). Our study on surfactant-depleted adult rat lungs seems to confirm their results.

Using the value of $7 \mathrm{~cm}^{2} / \mathrm{g}$ body weight (13) for the lung surface areat. We found that the surface area of the lung of a 500 gr rat is $3.50\left(0 \mathrm{~cm}^{2}\right.$. Since Fujiwara et al. (4) determined that the amount of DPL per unit surface area required to produce stable lungs was $5.7 \times 10^{-4} \mathrm{mg} / \mathrm{cm}^{2}$, we calculated that about $2 \mathrm{mg}$ DPL were required to replace the surfactant of the washed rat lungs. We showed in our study that instillation of a natural surfactant solution containing $4 \mathrm{mg}$ total phospholipids (2 mg DPL) was enough to restore the pressure-volume characteristics of washed lungs. Instillation of $10 \mathrm{mg}$ synthetic DPL, however, did not succeed in restoring pressure-volume characteristics. The discrepancy in efficacy of DPL compared to natural surfactant could be a result of the properties of the solvent used with DPL suspension or a lack of some other compound which is present in the natural surfactant suspension.

Our method of delivering natural surfactant to the lungs offers several practical and theoretical advantages that might enhance correction of alve(olar surfactant deficiency. More studies will be necessary to determine the physical and chemical differences between natural surfactant and synthetic DPL.

\section{CONCLUSION}

Excised rat lungs from which surfactant was removed by washing with saline were treated by four different methods in an attempt to restore the PV characteristics to normal. The four methods were: nebulization of DPL, instillation of DPL, nebulization of natural surfactant, and instillation of natural surfactant. Results were analyzed from the deflation limb of the PV curve and expressed as pereentage of TIC.

Using the techniques employed in this study, instillation of natural surfactant was the only method which restored the PV characteristics of surfactant-depleted lungs to normal.

\section{REFERINNCES AND NOTES}

1. Chu, J., Clements, J. A., Cotton, F. K., Klaus, M. H., Sweet, A. Y.., and Tokoley, W. H.: Neonatal pulmonary ischemia. Pediatrics, 40: 709) (1967)

2. Fnhörning, (i., and Robertson, B.: Lung expansion in the premature rabbit fetus after tracheal deposition of surfactant. Pediatrics, $50: 58$ (1972)

3. Fujiwara, T., Adams, F. H., Sipos, S., and 1:1-Salawy, A.: "Alveolar" and whole lung phospholipids of the developing fotal latub lung. Amer. J. Physiol. 215: 375 (1968).

4. Fujiwara, T., Adams, F. H., Nozaki, M., and Dermer, (j. B.: Pulmonary 
surfactant phospholipids from turhey lung: (omparison with rabbit lung. Amer. J. Physiol., 218: $218(1970)$.

5. Farridy, F. I., Permutt, S., and Riley, R. 1.: Effect of ventilation on surface force in excised lungs. J. Appl. Physiol., 21: 1453 (1966)

6. Forest. J. B.: The effect of hyperventilation on the size and shape of alveoli Brit. J. Anacsthesiol., 42: 810 (1970))

7. Gribety, I., Frank, N. R., and Avery, M. L.: Static volume-pressure relations of excised lungs of infants with hyaline membrane disease, newborn and stillbern infants. J. ( lin. Invest., 38: $2168(1959)$.

8. Johnson, R. P.. Ievine, B. I.., and Cummings, I. G.: Alteration of pulmesnary surfactant and quasi-static pressure-solume relationships in rat lungs. Fed. Proc., 23: $150(1964)$

9. MeC (lenahan, J. B.. and Urtnowsi. A.: Iffect of ventilation on surfactant and its turnover rate. J. Appl. Physiol., 23: $215(1967)$

10. Pattle. R. 1.: Surface lining of Jung alveoli. Physiol. Rev., 45: $48(196,5)$.

11. Robertson, B. and Enherning. (j.: The alveolar lining of the premature newborn rabbit after pharyngeal deposition of surfactant. Lab. Invest. 3/ $54(1974)$

12. Shamnon. D. C. Kazemi, H., Merril, IE. W.. Smith, K. A., and Wong, P. S L.: Restoration of volume-pressure curves with lecithin fog. J. Appl. Physiol., 28: $470(1970)$.

13. Weibel, E. R.: Postnatal growth of the lung and pulmonary gas-exchange capacity In: A $V$ S Dekeuch, and $R$. Porter: Development of Lung. (Little Brown, Boston, 1967)

14. These studies were supported by funds from the United States Public llealth Service and the National (ystic Fibrosis Research Foundation.

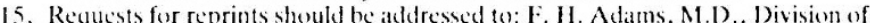
Carctiology, Department of Pediatries. University of California. School of Medicine, Center for the Health Sciences, Los Angeles, California 90024 (USA).

16. Received for publication March 24. 1976.

17. Acecpted for publication September 1. 1976
Aldosterone newborn

dict

kidney

\title{
Plasma Aldosterone Concentrations during the Neonatal Period
}

\author{
M. ('. RAUX-IUURIN, ${ }^{1 N \prime}$ M. T. PHAN-HUU-TRUNG, D). MARRE(', ANI) F. (IIRARI) \\ Laborateire de Physiologie Endecrinienne Infantile, INSER,Y U 1+2, Mopital Troussean, Paris, France
}

\begin{abstract}
Summary
The direct radioimmunoassay for plasma aldosterone (PA) set up in this laboratory has been reported elsewere. Subjects were 115 normal full term newborns and infants. During the first week of life, there was a wide dispersion in the PA levels $(<1-$ $445, n=89)$, but on the whole these levels were high $(>6 \mathrm{ng} /$ $100 \mathrm{ml}$ ) and $35 \%$ were higher than those observed in children after stimulation $(>48 \mathrm{ng} / 100 \mathrm{ml})$. Furthermore, there was a negative correlation between P $A$ values and the day of sampling $(P<0.01)$. In older infants, $P A$ values sere lower and the ranges narrower. $A$ highly significant negative correlation was found between Na:K ratios and $P A$ levels. The mean geometrical value for PA levels was $53 \mathrm{ng} / 100 \mathrm{ml}$ vs. 1.012 for Na:K mean ratio. When related to weight variations, $P A$ values were randomly distributed. No correlation was found between $P A$ and sodium intakes. The daily urimary excretion of tetrahydroaldosterone and 3-oxoconjugate of aldosterone were lower per se, but when related to surface area, were found to be roughly 3 fold those of control adult subjects. We conclude that in the newborn, both the production and excretion of aldosterone are different than values in the adult and that responses to the regulation factors mentioned above are decreased.
\end{abstract}

\section{Speculation}

The direct radioimmunoassay of $P A$ facilitates the evaluation of this hormone during the neonatal period and infancy. The results obtained from plasma and urinary determinations of aldosterone provide evidence for a different pattern of both production and metabolism of aldosterone during these periods. $A_{n}$ appreciation of these $P A$ values and of their regulation is necessary in order to evaluate the significance of $P A$ levels observed in pathologic cases.
It has previously been reported that PA levels are dramatically clevated during the neonatal period $(3,11)$ and infancy $(5,8)$. However, apart from this common point, the results obtained have been widely dispersed and all authors have found values overlapping those observed in the adult. We undertook the present study in order to obtain further information on PA fevels, especially during the neonatal period, and to try and relate the results we obtained with a physiologic index of aldosterone activity or regulation.

\section{NIE:TH(ODS}

\section{MI:THOD FOR MI:ASURINHENT OF PA}

The direct radioimmunoassay set up in this laboratory hats been reported elsewere (11). One milliliter of plasma was extracted with $10 \mathrm{ml}$ methylene chloride and the extract washed first with $1 \mathrm{ml}$ of $0.1 \mathrm{M} \mathrm{Na(OH}$ and then with $1 \mathrm{ml}$ distilled water. Different aliquots of the extract, determined according to the expected aldosterone concentrations, were assayed without further purification with the aid of a highly specific antibody. The sensitivity of the assaly was $1 \mathrm{ng} / \mathrm{log}(\mathrm{ml}$ plasma. Some plasma samples from newborns were submitted to Sephadex LH20 chromatography as described by Murphy (9), using a methylene chloride-methand (9s:2) solvent.

\section{URINARY NII:IABOIIIIS OI: ALDOSIIRONI}

These were assalyed by radioimmunoassay after column chromatography.

\section{SUBJI:CTS}

The subjects were 115 normal full term newborns and infants. Blood samples were taken from the antecubital vein of the 